\title{
Personal and Political Correctness: A Content Analysis of Leading Politicians Instagram Account in Indonesia
}

\author{
Irmawan Rahyadi ${ }^{1}$, Amy Mardhatillah $^{2}$, Rustono Farady Marta ${ }^{3}$, Tamimi Zakirah ${ }^{4}$ \\ \{irmawan.rahyadi@binus.edu ${ }^{1}$ \} \\ Communication Department, BINUS Graduate Program, Master of Strategic Marketing Communication, \\ Bina Nusantara University ${ }^{1,4}$ \\ Psychology Department, Mercubuana University, 11650, Indonesia ${ }^{2}$ \\ Communication Department, Bunda Mulia University, 14430, Indonesia ${ }^{3}$
}

\begin{abstract}
Positioning political party opens a relationship between leaders and their stakeholders. A common theme in adopting relationship online is that social media platform needs more attention to be beneficial. This article looks at how leading politicians value Instagram as communication platform and how Covid-19 pandemic message communicated by the actors within the platform. Content analysis was conducted on five leaders of large political party in Indonesia to understand their value and communication code in their postings. From the data, the study revealed younger politicians tend to value the platform more than others in the way of following the trends and showing their personal characteristic instead of political and professional characteristic.
\end{abstract}

Keywords: Instagram; Covid-19; content analysis; political party; politician

\section{Introduction}

As the opening quotation suggests, the bio section in Instagram account from one of leaders of political party in Indonesia showed personal touch, which is a sign of self-representation. One of the most important social media in Indonesia is Instagram, which is listed as the number 4 biggest social media in Indonesia and used by 126,4 million people [1]. Instagram is defined as a chosen platform for celebrities, actors, even government officials to share information and daily activities to publics. The establishment of Instagram has been connected to the capturing everyday activities in photo or video like a new norm as a daily life document [2]- [5]. Furthermore, a large portion of Instagram content comes from raw materials that cultivated to create intimacies between participants and audiences as well as how 'raw' contents produced by users [6].

This study argues that the platform allows opportunity for wider variety of personalities and overlapping relationship between public and private as well as forging relationship [7]- [9]. The production of content and sharing visual content applied to niche interest in Instagram, suggesting that the world has greater recognition to the practice of Instagram users [10]. However, the utilization of Instagram by politicians proven to be more successful compared to the political institution as well as "communitainment" [11] [12]. The spread of Instagram utilization within political field is then a apart of a wider discussion in mobilization, user engagement, and promotion [13] [15]. 


\section{Method}

We focus on Instagram official accounts of politician who have a consistent presence in the platform and offer public free access to their political, professional, and personal viewpoint. Head of large political party is our focus. Instagram postings from pre-March 2020, along with other older account details, were excluded from our sample. The materials for this research consisted of Instagram postings (during March 2020-recent) that fixated on five leaders of political party in Indonesia. The materials were gathered through identifying political parties' website, Instagram field research, narrowing to five leaders that consistently active and engage in Instagram as their communication platform. Account bio, the number of posts, number of followers, number of following available from Instagram platform are also studied.

The politicians were chosen based on presence in the platform for an extended period and were thus posting and showing familiarity with the Instagram conversation and noticed by other Instagram users. Five politicians were leaders of large political parties in Indonesia from different political positioning (governmental supporter and opposition). The data gathering was conducted the early August until the end of August, with postings from these accounts pinpointed from their official accounts. The politicians first identified from the party official websites, their presence in Instagram then explored and their consistent quantity of posting in the platform was the criteria for the sample candidates. Each posting was studied to show their point of view on what current happenings in relations to Covid-19 pandemic from their Instagram feed. The postings were categorized to reflect on the type of political, professional, and personal position in the nation as well as their engagement with their stakeholders and the activities of these politicians as politician, executive, public figure, and public officials.

\section{Results and Discussion}

As the data analysis took place from all the postings within the research period, it revealed that the politicians deployed different approaches in the management of their Instagram account, for example, personal activities with family, me-time moment, and comedy content (AHY, Cak Imin) compare to serious international, national-level meeting attendance and photos with the president (Airlangga, Zul, HT). The example from the two Instagram postings caption further illustrates this comparison:

a. "This is the time for me and Annisa confused about choosing a wedding ring, for single men and single women, don't worry about choosing a wedding ring, worry about choosing your soul mate" (AHY)

b. "Today I attended the signing of a cooperation agreement on the corporate guarantee program for the national economy recovery at the Mezzanine Hall, Ministry of Finance, Wednesday (29/7) ..." (Airlangga)

In the above quote, it appears that anything that related to personal touch on these Instagram data is came from younger personality and opposition (AHY) to signal quality of prestige of being real person not only serious political message, which legitimates political leadership as the point of self-representation for differentiation from the rest. This data also emphasizes how important political figure in the country also produce proximity to public by posted photo / video of their personal space and story, which in turn enforces non-organizational rigidity of what viewed as political power in how to become acknowledged and valued. A serious political identity thus bears distance from the public in general for this personality. 
What constitutes a national-class personality is, nevertheless, created in deculturalize (national) and depoliticized (open for all) behavior without explicit political message and connotation constantly in the Instagram postings. In the following section, the data shows how such messages become a communication tool in Covid-19 pandemic issue.

\subsection{Personal characteristics}

The starting point of communication via Instagram is that photo (and video) is never stands alone: where there is power, there is responsibility. Although, another fundamental issue regarding standard information of Covid-19 pandemic revolves around numbers and drug, people still need to be reminded as to health protocol and lockdown procedure of a certain places around the country. Issue such as Covid-19 pandemic is one of the national agenda, in which these politicians carry a moral and political responsibility to use their power to encourage other (even within their own institution) to at least aware of the issue and in a way educate the public.

Airlangga represents himself as a serious political leader in Instagram from his posting with less personal touch. Most of the posts (photo and video) are staged and constructed as public officials. His only family members that captured in the Instagram post is his wife in her capacity as the first lady in the ministry.

Meanwhile, Cak Imin shows some personal characteristics to his public by posting photo of his family members and family activities, not only his wife. In his feed from earlier March when Covid-19 outbreak identified until August, Cak Imin posted his personal space, his dining table at home, his living room space, his home office, bicycling with his friends, old photos from 14 years ago, etc. The old photo that he posted, following Instagram users open challenge when celebrities started to post their old photos when they are still clueless. He also reposted some funny and comedy video and photos to entertain his followers. In his Instagram feed, his standard of self-representation remains light voluntarily but is sometimes cited as serious, thus giving his followers an access to his personal characteristic that appears to be his personal traits and his followers (mostly political) is conveniently assumed that proximity is Cak Imin's personal status. In other posts, his caring message looks easily flow because he used to carry a light message. For example, on April 1, his video encouraging people to keep a healthy routine and reach out for help if need help shot from his living room with a modest camera and lighting setting. In his serious photos behind a podium as a keynote speaker or photos side by side with prominent national figures, however, it was still comedically captioned with slangs and words that millennial say routinely. Even so, it is important to remain aware that compliance with the political standard does not of itself confer comedically from messages, as Cak Imin practiced in his Instagram posts.

Nonetheless, recent posts since March 2020 from AHY has shown that personal space also means postings photos with his loved ones (daughter, wife, dad, mom, brother, and niece), one that has on his causal occasion when he played swing with his daughter. Doubtless, younger than any politician in this study, AHY follows trends in social media, such as posting his old photos with his wife when they still on a date. The tendency of AHY savviness in social media management (using his own smartphone to post content) has become standard not only because he is in his young age but also, he is potentially going to participate.

In contrast, Zulkifli as the head of PAN in one post showed he was walking out from an office with West Java Governor. This far more concerned with his serious political figure showing political support to the elected governor, whether what was done was reasonable in the circumstances is a valid question because of his political position. However, posting a video with his granddaughter, photo of strolling around with his wife, video of his whole family during 
Id prayer in his living room are some of the posts that show his personal characteristic in front of his followers.

The self-representation for Harry Tanoe in Instagram shows his political message in least quantity compare to his business side as Executive Chairman of MNC (one of the largest media companies in Indonesia). His personal touch on the postings shows from his postings about his family members (wife, grandchildren, and children).

\subsection{Professional and political characteristics}

AHY brings a unique treat in terms of Instagram postings. He appears to have real individual image in the social media compare to Airlangga, Cak Imin and Zulkifli, these three officiate in the legislative and executive. While Harry Tanoe is an executive in the large media company. With the fact that for the most part, they are the head of large political party in Indonesia and have a reasonable follower as to what might constitute a standard professional and political self-representation in social media. They also cannot cater for misplaced of message that, for whatever reason, might demand a more attentive communication option. The extent of professional and political characteristics benefits the politicians in terms of their personal branding because of their leading position in the political institution. For example, Harry Tanoe as a self-made successful businessman who founded a political party, so his postings also consist of some motivational content in the form of video and photo with insightful caption. The finding in the data for his Instagram account is that political message blend (even obscure) with another message that he tries to convey

\section{Conclusion}

Using this content analysis lens, we have addressed the self-representation and communication of leading politicians in Instagram and connect that with Covid-19 pandemic. We presented how these politicians positioned themselves in social media platform which heavily focus on still images and video, places in which the public could gain national conversational pieces and political educational material. Yet our analysis of the online interpretations of the national- level individuals and the identification differences illustrated the modes and communication models to their stakeholders and public in general. Our results have thus shown how politicians show their true color in terms of how they position and value the social media platform, which naturally embedded with high potency in communication power for advertisement purposes, political image, engagement pods and social utility purposes.

Our results have thus indicated how images and videos manifest in communicate their political position of a national and culturally fused political education and the ideal portrait of politician in the eyes of public. As discussed above, since the early March 2020, the politicians' message has shown their truly caring positioning as a national public figure as well as their current leading position in the government or company. Such a positioning and selfrepresentation reflect politician management and value on the platform. As much as they value the platform, to the point of using their own smartphone to post to their Instagram account, the platform values them back by at the minimal level to verify their accounts. But the value and message need to relate to each other. There is time and efforts to communicate in this platform to get the message across and to benefit fully from the platform. The strong commitment to entertain, educate and just to greet (as Cak Imin mentions in his Bio section) the followers 
demonstrated by these politicians in a diverse type of way which implying that politicians are eager to change and adopt to newer communication channel (either self-aware or educated) and to play a greater role in the development of the national political conversation. Although the determination of personality like AHY which founded as having the highest determination in valuing the platform as communication channel, whether personality such as Airlangga low value to the Instagram platform (the rigid and template-based content) is subject to discussion. As a literature argues, Instagram is used mainly for broadcasting instead of mobilizing. The personalization of the leader is important in party's image.

In relations to Covid-19 pandemic issue positioning, all the politicians show awareness and post photos and video where they obey government instruction such as physical distancing and wearing a mask. To take up a notch, Cak Imin posted a video addressing this health protocol issue. These politicians also mirror what happenings in Indonesia, when lockdown until new normal was implemented, we can see the development of the condition of the nation coping with the pandemic not necessarily reading the text.

\section{Acknowledgment}

We would like to express our special thanks for all the support to finish this article. We would also like to extend our gratitude to Bina Nusantara University for supporting our research.

\section{References}

[1] S. Kemp, "Digital Around The World in April 2020," 2020.

[2] Z. Ben Taleb, L. I. Laestadius, T. Asfar, B. A. Primack, and W. Maziak, "\#Hookahlife: The Rise of Waterpipe Promotion on Instagram,” Heal. Educ. Behav., vol. 46, no. 1, pp. 106-113, Feb. 2019, doi: $10.1177 / 1090198118779131$

[3] A. Caliandro and J. Graham, "Studying Instagram Beyond Selfies," Soc. Media Soc., vol. 6, no. 2, 2020, doi: 10.1177/2056305120924779.

[4] K. Moore and G. Craciun, "Fear of Missing Out and Personality as Predictors of Social Networking Sites Usage: The Instagram Case,” Psychol. Rep., 2020, doi: 10.1177/0033294120936184.

[5] L. van Driel and D. Dumitrica, "Selling brands while staying 'Authentic': The professionalization of Instagram influencers," Convergence, 2020, doi: 10.1177/1354856520902136.

[6] J. Reade, "Keeping it raw on the 'gram: Authenticity, relatability and digital intimacy in fitness cultures on Instagram," New Media Soc., 2020, doi: 10.1177/1461444819891699.

[7] S. P. Caldeira, S. De Ridder, and S. Van Bauwel, "Between the Mundane and the Political: Women's Self-Representations on Instagram," Soc. Media Soc., vol. 6, no. 3, 2020, doi: 10.1177/2056305120940802.

[8] S. Duguay, "'Running the Numbers': Modes of Microcelebrity Labor in Queer Women's SelfRepresentation on Instagram and Vine," Soc. Media Soc., vol. 5, no. 4, 2019, doi: $10.1177 / 2056305119894002$.

[9] E. Locatelli, "Images of breastfeeding on instagram: Self-representation, publicness, and privacy management," Soc. Media Soc., vol. 3, no. 2, 2017, doi: 10.1177/2056305117707190.

[10] K. Toffoletti, A. Pegoraro, and G. S. Comeau, "Self-Representations of Women's Sport Fandom on Instagram at the 2015 FIFA Women's World Cup," Commun. Sport, 2019, doi: $10.1177 / 2167479519893332$.

[11] A. O. Larsson, "Winning and losing on social media: Comparing viral political posts across platforms," Convergence, vol. 26, no. 3, pp. 639-657, 2019, doi: 10.1177/1354856518821589. 
[12] S. Stollfuß, "Communitainment on Instagram: Fitness Content and Community-Driven Communication as Social Media Entertainment," SAGE Open, vol. 10, no. 2, 2020, doi: $10.1177 / 2158244020919535$.

[13] A. O. Larsson, "Skiing all the way to the polls: Exploring the popularity of personalized posts on political Instagram accounts," Convergence, vol. 25, no. 5-6, pp. 1096-1110, Dec. 2019, doi: $10.1177 / 1354856517741132$.

[14] J. Lindholm, T. Carlson, and J. Högväg, "See Me, Like Me! Exploring Viewers' Visual Attention to and Trait Perceptions of Party Leaders on Instagram," Int. J. Press., 2020, doi: 10.1177/1940161220937239.

[15] S. J. Turnbull-Dugarte, "Selfies, Policies, or Votes? Political Party Use of Instagram in the 2015 and 2016 Spanish General Elections," Soc. Media + Soc., vol. 5, no. 2, p. 205630511982612 , Apr. 2019, doi: 10.1177/2056305119826129. 